\title{
Determination of Aucubin and Catalpol in Plantago Species by Micellar Electrokinetic Chromatography
}

Renata Jurišića,*, Željko Debeljak ${ }^{\mathrm{b}}$, Sanda Vladimir-Kneževića ${ }^{\text {, }}$ and Jadranka Vukovića

a Faculty of Pharmacy and Biochemistry, University of Zagreb, A. Kovačića 1, HR-10000 Zagreb, Croatia. Fax: +385-1-4920089. E-mail: rjurisic@pharma.hr

b PLIVA, Pharmaceutical Industry, Research and Development, Analytical Development, Prilaz baruna Filipovića 25, HR-10000 Zagreb, Croatia

* Author for correspondence and reprint requests

Z. Naturforsch. 59c, 27 -31 (2004); received December 13, 2002/June 11, 2003

Micellar electrokinetic chromatography (MEKC) was used for the separation and determination of two iridoid glycosides, aucubin and catalpol, in several Plantago species growing in Croatia: $P$. altissima L., P. argentea Chaix, P. coronopus L., P. holosteum Scop. (subsp. depauperata, subsp. holosteum and subsp. scopulorum), P. lagopus L., P. lanceolata L., and P. maritima L. Hot water extraction (HWE) was applied for the isolation of iridoid substances. Significant differences appeared between the iridoid contents in the examined species. The yield of aucubin and catalpol was up to $0.27 \%$ and $1.81 \%$ of the dry mass of the leaves, respectively. Besides aucubin and catalpol, two related compounds were determined in the plant samples.

Key words: Plantago, Micellar Electrokinetic Chromatography, Iridoid Glycosides

\section{Introduction}

The genus Plantago L. comprises 265 species and has cosmopolitan distribution (Taskova et al., 2002). Medicinally, they are astringents, demulcents, emollients, expectorants, diuretics, antibacterials and antivirals (Marchesan et al., 1998; Samuelsen, 2000). In recent years, a considerable number of different iridoids have been isolated from the genus Plantago, and these include aucubin, catalpol and biosynthetically related compounds (Handjieva et al., 1993; Damtoft et al., 1994; Jensen et al., 1996; Rønsted et al., 2000).

Iridoids are naturally occurring monoterpenic products of plants that can be divided into four groups: iridoid glycosides, aglycone or non-glycosidic iridoids, secoiridoids and bisiridoids (Suomi et al., 2000). The occurrence of iridoids has been discussed in detail in the following families: Acanthaceae, Lamiaceae, Plantaginaceae, Rubiaceae and Scrophulariaceae (Inouye et al., 1988; Jensen et al., 1988; Junior, 1990; Andrzejewska-Golec, 1995). The considerable interest in iridoids has been generated by their relatively wide spectrum of biological activity (Andrzejewska-Golec, 1995), as well as by their use as markers in plant taxonomy (Andrzejewska-Golec et al., 1993; Andrzejewska-Golec, 1997; Müller et al., 1999; Taskova et al., 2002). Among the complex mixture of biologically active compounds in the plant extracts, the iridoid glycosides aucubin and catalpol can be used as analytical markers to determine the quality of extracts from different sources (Rischer et al., 1998).

Iridoids have usually been isolated from the sample matrix by maceration with solvents, mainly methanol or ethanol. Suomi et al. (2000) showed that extraction methods differed in their efficiency for extracting aucubin and catalpol from Veronica longifolia leaves. The best results were obtained using hot water extraction (HWE) at $100{ }^{\circ} \mathrm{C}$ and atmospheric pressure. The recovery of aucubin and catalpol standard compounds with this method was above $90 \%$. Aucubin and catalpol mass fractions (\% iridoids/dry mass) were at least 2 times higher than those determined after extractions with methanol, ethanol and 2-propanol. The HWE technique also exhibited better repeatability and is more environmentally friendly than conventional isolation techniques.

The iridoid glycoside typical feature is a partly hydrogenated cis-fused cyclopenta- $[c]$ pyran system, which arises from the intramolecular acetalisation of a 1,5-cyclopentandialdehyde moiety and usually is stabilized by acetalisation or esterification. Since iridoids are hydrolysed and subse- 
quently rearranged even under mildly acidic conditions, all analyses must be performed in basic buffer solutions. Basic conditions are an advantage in capillary electrophoresis because the electroosmotic flow increases and thus the migration times of analytes as well as the total analysis time decrease. Only a few reports on the analysis of iridoids by capillary electrophoresis (CE) have been published (Wu et al., 1998; Suomi et al., 2000; Suomi et al., 2001a). According to them, several iridoid glycosides can be successfully separated by MEKC. The advantages of this approach lie in fast analysis, satisfactory resolution between iridoids and their good separation from the rest of the sample.

The aim of the present study was to determine aucubin and catalpol (Fig. 1) contents in extracts of several Plantago species adapting MEKC method introduced by Suomi et al. (2000). Regarding to aucubin and catalpol contents, plant species examined in this work have not been quantitatively analysed before, except $P$. lanceolata (Suomi et al., 2001b), which was used as a reference specimen.

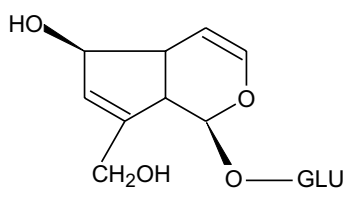

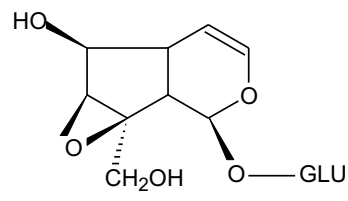

2
Fig. 1. Structures of aucubin (1) and catalpol (2).

\section{Materials and Methods}

\section{Plant material}

Wild growing Plantago species: P. altissima L., $P$. argentea Chaix, P. coronopus L., P. holosteum Scop. (subsp. depauperata, subsp. holosteum and subsp. scopulorum), P. lagopus L., P. lanceolata L., and $P$. maritima L. were collected in June 2000 in Istria and on the islands of Cres and Lošinj, Croatia. All plant samples were kindly identified by Professor Ivan Šugar (Department of Pharmaceutical Botany, Faculty of Pharmacy and Biochemistry, University of Zagreb, Croatia). Voucher specimens (No. 0061-0069) are deposited in the Herbarium of the Department of Pharmacognosy (Faculty of Pharmacy and Biochemistry, Univer- sity of Zagreb, Croatia). Air-dried samples of old leaves were investigated.

\section{Standards and reagents}

Aucubin and catalpol standards were donated by Dr. Søren Rosendal Jensen (Technical University, Lyngby, Denmark). The compounds had been extracted from plant material with ethanol, purified by RP-HPLC and identified by UV detection at wavelengths 206 and $254 \mathrm{~nm}$. Weighed standard substances were dissolved in water. In order to improve the analytical method accuracy, three standard aucubin and catalpol concentration levels were prepared $(0.05,0.075$ and $0.1 \mathrm{mg} / \mathrm{ml})$. Disodium tetraborate decahydrate $\left(\mathrm{Na}_{2} \mathrm{~B}_{4} \mathrm{O}_{7} \cdot 10 \mathrm{H}_{2} \mathrm{O}\right)$ and $\mathrm{NaOH}$ were obtained from Kemika d.o.o. (Zagreb, Croatia), while sodium dodecyl sulphate (SDS) was obtained from Merck (Darmstadt, Germany). Water used in experiments was double distilled and deionised with a Clear instrument (SG, Hamburg, Germany). Final electrical resistance of water was $18 \mathrm{M} \Omega$.

\section{Sample preparation}

The powdered leaf material (200 mg) was weighed to accuracy within $0.1 \mathrm{mg}$. This was followed by the hot water extraction (HWE). The samples were weighed into vials and purified water was added. The mixture was kept at room temperature for $40 \mathrm{~min}$ to wet the samples thoroughly and then heated at $100{ }^{\circ} \mathrm{C}$ in the heating block for $60 \mathrm{~min}$. The extracts were evaporated to dryness and then partitioned between water and diethyl ether. Since the iridoid glycosides are highly polar compounds, diethyl ether did not extract the iridoid compounds at all. The water phase was filtered and water was added up to volume of $4 \mathrm{ml}$. The samples were prepared in duplicate and injected twice.

Prior to the analysis, all standard and sample solutions were filtered through Waters sterile filters, pore size $0.20 \mu \mathrm{m}$.

\section{Apparatus and analytical procedure}

${ }^{3 D}$ CE (Hewlett-Packard, Avondale, PA, USA) capillary electrophoretic system equipped with an UV/VIS diode array detector was used. Uncoated silica capillaries were supplied by Composite Metal Services (The Chase, Hallow, UK). The total length of capillaries was $35 \mathrm{~cm}$, while the effec- 
tive length was $26.5 \mathrm{~cm}$. Internal and external diameters were 50 and $375 \mu \mathrm{m}$, respectively.

The most suitable set of conditions for determination of iridoid glycosides by the employed MEKC method included electrolyte composed of $50 \mathrm{mmol} / \mathrm{l}$ borate and $180 \mathrm{mmol} / \mathrm{l} \mathrm{SDS}$, adjusted to $\mathrm{pH}=9.35$, wavelengths of $200 \pm 2 \mathrm{~nm}$ and $250 \pm$ $30 \mathrm{~nm}$, voltage $10 \mathrm{kV}$, current $80 \mu \mathrm{A}, 50 \mathrm{mbar} \times 5 \mathrm{~s}$ injection, and cassette temperature of $25^{\circ} \mathrm{C}$. Preconditioning was somewhat altered, compared to methodological data described by Suomi et al. (2000). Instead of an $8 \mathrm{~min}$ flush with electrolyte, a 3 min flush was used. After 6 consecutive runs, conditioning run followed. Conditioning run consisted of $10 \mathrm{~min}$ flush with $0.1 \mathrm{mmol} / \mathrm{l} \mathrm{NaOH}$ and a 20 min flush with electrolyte was followed by a 15 min electrophoretic run.

Replenishment of electrolyte vials was used. These changes were introduced in order to make sequential analysis simple and continuous.

\section{Results and Discussion}

Due to the complexity of the plant material and the structural similarity of iridoid glycosides, MEKC was selected to separate these compounds. The method was found efficient in separation and quantitative analysis of aucubin and catalpol in various Plantago species.

The first choice for the separation of aucubin and catalpol from the plant extracts was a thinlayer chromatography (TLC) (Wagner et al., 1983). The problem with TLC was the poor resolution. Some aucubin and catalpol related compounds present in plant samples were poorly separated from the analysed compounds and this could lead to false spot assignment. High performance liquid chromatography (HPLC) was not taken into account due to its long run time and disability to resolve iridoids as a separate peak cluster. These considerations lead to capillary electrophoresis (CE). Since aucubin and catalpol have very high $\mathrm{p} K_{\mathrm{a}}$ values $(>12)$, these molecules are non-ionogenic and they cannot be separated by the conventional capillary zone electrophoresis (CZE). Therefore, sodium dodecyl sulphate (SDS) was used as a micelle-forming substance in the electrolyte solution. High micelle concentrations were needed to separate aucubin and catalpol with their similar structures (Suomi et al., 2001a).

In order to improve separation between aucubin and catalpol peaks, a slightly longer capillary was used compared to the previously reported method (Suomi et al., 2000). Instead of $33.5 \mathrm{~cm}$, a total length of $35 \mathrm{~cm}$ was used, with constant current limit of $80 \mu \mathrm{A}$. Injection volume was not decreased, because it would decrease the method sensitivity, although it could improve resolution. Final resolution between analytes was approximat 2 , which was measured with the tangent method. The drawback was a slightly longer run time of $12 \mathrm{~min}$. Problems related to poor resolution between aucubin and catalpol mentioned in literature (Suomi et al., 2001b) were solved this way (Fig. 2). Fig. 3 suggests that this method could also be used for fingerprint analysis. Sensitivity improvement was achieved by lowering the detector response time to $2.6 \mathrm{~s}$ coupled with narrow main signal bandwidth $( \pm 2 \mathrm{~nm})$. Slower migration times of both analytes increased sensitivity. A somewhat lower current limit caused slower analyte migration, which in turn caused peak area increase, without significant peak broadening. The signal to noise ratio for $0.05 \mathrm{mg} / \mathrm{ml}$ concentrations was 150 for au-

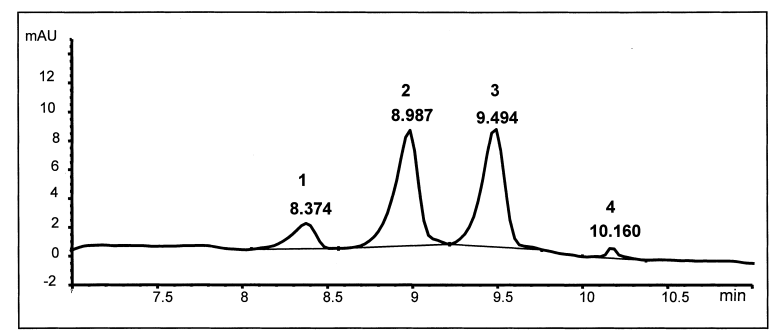

Fig. 2. Electropherogram of iridoid substances $\mathbf{1 - 4}$ in Plantago lanceolata L. 1, Iridoid related substance No. 1; 2, catalpol; 3, aucubin; 4, iridoid related substance No. 2. MEKC conditions: uncoated silica capillary, $50 \mu \mathrm{m}$ i.d. $\times$ $35 \mathrm{~cm}$; running buffer, $180 \mathrm{mmol} / 1 \mathrm{SDS}$ and $50 \mathrm{mmol} / 1$ borate $(\mathrm{pH}=9.35)$; separation voltage, $10 \mathrm{kV}$; current, $80 \mu \mathrm{A}$; injection, $50 \mathrm{mbar} \times 5 \mathrm{~s}$; wavelengths, $200 \pm 2 \mathrm{~nm}$ and $250 \pm 30 \mathrm{~nm}$; cassette temperature, $25^{\circ} \mathrm{C}$.

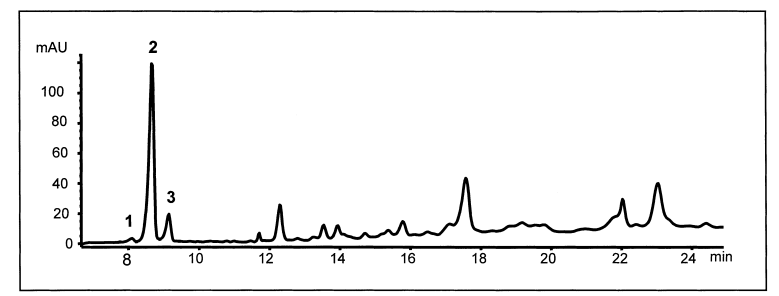

Fig. 3. Electropherogram of a Plantago argentea Chaix aqueous extract. 1, Iridoid related substance No. $1 ; \mathbf{2}$, catalpol; 3, aucubin. MEKC conditions are the same as in Fig. 2. 
Table I. Aucubin and catalpol contents in Plantago species.

\begin{tabular}{|c|c|c|c|c|c|c|c|c|}
\hline \multirow[b]{2}{*}{ Sample name } & \multicolumn{4}{|c|}{ Aucubin } & \multicolumn{4}{|c|}{ Catalpol } \\
\hline & $\begin{array}{c}\text { Average } \\
\text { yield (\%) }\end{array}$ & $\begin{array}{l}\text { Standard } \\
\text { deviation }\end{array}$ & $\begin{array}{c}\mathrm{LCL}^{\mathrm{a}} \\
(0.05 \%)\end{array}$ & $\begin{array}{l}\mathrm{UCL}^{\mathrm{b}} \\
(0.05 \%)\end{array}$ & $\begin{array}{c}\text { Average } \\
\text { yield (\%) }\end{array}$ & $\begin{array}{l}\text { Standard } \\
\text { deviation }\end{array}$ & $\begin{array}{c}\mathrm{LCL}^{\mathrm{a}} \\
(0.05 \%)\end{array}$ & $\begin{array}{l}\mathrm{UCL}^{\mathrm{b}} \\
(0.05 \%)\end{array}$ \\
\hline P. altissima & 0.092 & 0.001 & 0.090 & 0.094 & 0.131 & 0.001 & 0.127 & 0.135 \\
\hline$P$. argentea & 0.273 & 0.004 & 0.267 & 0.278 & 1.809 & 0.031 & 1.767 & 1.852 \\
\hline P. coronopus & $<\mathrm{LOD}^{\mathrm{c}}$ & & & & $<\mathrm{LOD}^{\mathrm{c}}$ & & & \\
\hline $\begin{array}{l}P \text {. holosteum subsp. } \\
\text { depauperata }\end{array}$ & 0.077 & 0.007 & 0.068 & 0.086 & $<\mathrm{LOD}^{\mathrm{c}}$ & & & \\
\hline $\begin{array}{l}P \text {. holosteum subsp. } \\
\text { holosteum }\end{array}$ & $<\mathrm{LOQ}^{\mathrm{d}}$ & & & & $<\mathrm{LOD}^{\mathrm{c}}$ & & & \\
\hline $\begin{array}{l}\text { P. holosteum subsp. } \\
\text { scopulorum }\end{array}$ & $<\mathrm{LOQ}^{\mathrm{d}}$ & & & & $<\mathrm{LOD}^{\mathrm{c}}$ & & & \\
\hline P. lagopus & 0.072 & 0.007 & 0.063 & 0.082 & 0.082 & 0.002 & 0.079 & 0.085 \\
\hline P. maritima & 0.027 & 0.003 & 0.021 & 0.034 & $<\mathrm{LOD}^{\mathrm{c}}$ & & & \\
\hline P. lanceolata & 0.115 & 0.010 & 0.098 & 0.132 & 0.159 & 0.001 & 0.152 & 0.166 \\
\hline
\end{tabular}

a Lower confidence limit.

b Upper confidence limit.

c Limit of detection.

d Limit of quantification.

cubin and 102 for catalpol. This suggests that both quantification limits are $5 \mathrm{mg} / \mathrm{l}$ or less.

Results obtained by the described analytical method showed significant variation of aucubin and catalpol contents among the examined species. Depending on the sample, aucubin yield was up to $0.27 \%$, while the percentage of catalpol was up to $0.16 \%$, except in $P$. argentea, which contained $1.81 \%$ of this iridoid (Table I). Among all analysed extracts that contained iridoids above the limit of detection (LOD), aucubin was more frequently present compared to catalpol. Only in the sample of $P$. coronopus aucubin was not observed. Besides $P$. coronopus, also $P$. holosteum subsp. holosteum and $P$. holosteum subsp. scopulorum did not contain significant amounts of any of analysed iridoids. The content of catalpol was generally higher than aucubin content in all cases where both analytes were present $(P$. altissima, $P$. argentea, $P$. lagopus, and $P$. lanceolata). It could be related to plant metabolic pathways and their kinetics, although it could be also a consequence of the different extraction recoveries.

Since the described analytical method successfully separates iridoids from the matrix components (Fig. 2), two unknown peaks detected in most samples could be assigned to iridoid related substances. It was also shown that the UV spectrum of the unknown peak No. 1 corresponds to the catalpol UV spectrum, while that of the unknown peak No. 2 corresponds to the UV spectrum of aucubin. Forerunning treatment for the sample preparation did neither degrade, nor modify aucubin and catalpol. That was confirmed by including a control run, as well as by applying the same procedure as performed with the leaves and standard substances. Moreover, to avoid possible misassignment, relative retentions $\left(R R_{\mathrm{t}}\right)$ of all peaks were used. The unknown iridoid-related substance No. $1\left(R R_{\mathrm{t}}=1.28\right)$ was present in all samples, while the unknown substance No. 2 $\left(R R_{\mathrm{t}}=1.54\right)$ was not detected in $P$. altissima, $P$. argentea and $P$. coronopus. Besides, some samples contained three or even four peaks, two of which were aucubin and catalpol, while in leaves of $P$. coronopus aucubin and catalpol were not detected but only the unknown iridoid substance No. 1 $\left(R_{\mathrm{t}}=8.240 \mathrm{~min} ; R R_{\mathrm{t}}=1.28\right)$. This excludes the possibility of misassignment.

The described analytical method has been successfully employed for separation and determination of iridoid substances in different Plantago species. This method is simple, reliable and efficient, characterised by very low quantification limits of investigated compounds. MEKC can also be used as a valuable tool in fingerprint analysis.

\section{Acknowledgements}

The authors would like to thank to Dr. Søren Rosendal Jensen for the iridoid standards, and to Goran Srečnik for technical support and useful suggestions. 
Andrzejewska-Golec E., Ofterdinger-Daegel S., Calis I., and Swiątek L. (1993), Chemotaxonomic aspects of iridoids occurring in Plantago subg. Psyllium (Plantaginaceae). Pl. Syst. Evol. 185, 85-89.

Andrzejewska-Golec E. (1995), The occurrence of iridoids in plants. Acta Soc. Bot. Pol. 64, 181186.

Andrzejewska-Golec E. (1997), Taxonomic aspects of the iridoid glucosides occurring in the genus Plantago L. Acta Soc. Bot. Pol. 66, 201-205.

Damtoft S., Falkesgaard E., and Jensen S. R. (1994), Iridoid glucosides from Plantago hookeriana. Phytochemistry 35, 1367-1368.

Handjieva N., Taskova R., and Popov S. (1993), 10-Hydroxymajoroside, an iridoid glucoside from Plantago cornuti Gouan. Z. Naturforsch. 48c, 827-829.

Inouye H., Nishimura H., Kanomi A., Okuda T., and Puff C. H. (1988), Chemotaxonomic studies of rubiaceous plants containing iridoid glycosides. Phytochemistry 27, 2591-2598.

Jensen H. F. W., Jensen S. R., and Nielsen B. J. (1988), Chemotaxonomy of the Acanthaceae. Iridoids and quaternary amines. Phytochemistry 27, 2581-2589.

Jensen S. R., Olsen C. A., Rahn K., and Rasmussen J. H. (1996), Iridoid glucosides in Plantago alpina and $P$. altissima. Phytochemistry 42, 1633-1636.

Junior P. (1990), Recent developments in the isolation and structure elucidation of natural occurring iridoid compound. Planta Med. 56, 1-13.

Marchesan M., Paper D. H., Hose S., and Franz G. (1998), Investigation of the antiinflammatory activity of liquid extracts of Plantago lanceolata L. Phytother. Res. 12 (Suppl. 1), S33-S34.

Müller A. A., Kufer J. K., Dietl K. G., Reiter S. A., Grau J., and Weigend M. (1999), Iridoid glucosides-chemotaxonomic markers in Loasoideae. Phytochemistry 52, $67-78$.
Rischer M., Adamczyk M., Ratz H., Hose S., Marchesan M., Paper D. H., Franz G., Wolf-Heuss E., and Engel J. (1998), Quantitative determination of the iridoid glycosides aucubin and catalpol in Plantago lanceolata L. extracts by HPTLC and HPLC. J. Planar Chromat. 11, 374-378.

Rønsted N., Göbel E., Franzyk H., Jensen S. R., and Olsen C. E. (2000), Chemotaxonomy of Plantago. Iridoid glucosides and caffeoyl phenylethanoid glycosides. Phytochemistry 55, 337-348.

Samuelsen A. B. (2000), The traditional uses, chemical constituents and biological activities of Plantago major L. A review. J. Ethnopharm. 71, 1-21.

Suomi J., Sirén H., Hartonen K., and Riekkola M.-L. (2000), Extraction of iridoid glycosides and their determination by micellar electrokinetic capillary chromatography. J. Chromatogr. A 868, 73-83.

Suomi J., Sirén H., Wiedmer S. K., and Riekkola M.-L. (2001a), Isolation of aucubin and catalpol from Melitaea cinxia larvae and quantification by micellar electrokinetic capillary chromatography. Anal. Chim. Acta 429, 91-99.

Suomi J., Wiedmer S. K., Jussila M., and Riekkola M.-L. (2001b), Determination of iridoid glycosides by micellar electrokinetic capillary chromatography-mass spectrometry with use of the partial filling technique. Electrophoresis 22, 2580-2587.

Taskova R., Evstatieva L., Handjieva N., and Popov S. (2002), Iridoid patterns of genus Plantago L., and their systematic significance. Z. Naturforsch. 57c, 42-50.

Wagner H., Bladt S., and Zgainski E. M. (1983), Drogenanalyse. Springer Publ., Berlin-Heidelberg-New York, pp. 136-137.

Wu H.-K., Chuang W.-C., and Sheu S.-J. (1998), Separation of nine iridoids by capillary electrophoresis and high-performance liquid chromatography. J. Chromatogr. A 803, 179-187. 